\section{Community Engagement,} Customer Engagement, and Changes in Behavior

\author{
Alexander Belyakov \\ Consultant, Certified Sustainability Professional \\ (ISSP-CSP), Toronto, ON, Canada
}

\section{Definitions}

There are various definitions of engagement in the academic and professional environment. Most of them are not widely accepted and can vary in different contexts (also in the energy industry).

In this article, customer engagement in an interdisciplinary sense is a process of the ongoing interactions between businesses and their customers. There is also the monetary value of the relationships and emotional connection. In this process, customers develop and demonstrate their values, attitudes, aspirations, needs, and concerns related to a brand, a selected product, service, or policy. WIIFM (what's in it for me) is critical for customers. Engagement may or may not result in loyalty or specific actions of customers related to product or service purchase, use, or policy processes. However, engagement substantially increases the chances of such actions.

Community engagement is a broader process compared to customer engagement, where various community groups (not just customers segmented by marketing criteria) and communities as a whole participate in the processes related to product/services delivery, policies, action plans, and so on relevant for the community. Community engagement usually foresees more communication and cooperation among its members, as well as higher chances and more variety of actions (not just purchasing behavior as studied in customer engagement).

Changes in behavior are among expected actions influenced by community and customer engagement and can include specific steps related to lifestyle, product/service search, purchase, use, switch between products/services, post-usage stage, and others.

\section{Introduction}

Community engagement in the energy field could be an exciting, challenging, and rewarding experience. What makes community engagement related to energy issues successful? The answer to this question can be found in the latest trends, sustainable development studies, sociology, psychology, consumer behavior theory, marketing, and communication studies. A broad approach should consider that community members have the variety of roles. Community engagement is "a process that requires nurturing and attention to the differential needs of individuals at different levels of engagement" (Case and Zeglen 2018). 
The United Nations Brisbane Declaration developed at the International Conference on Engaging Communities (Brisbane, Australia, 2005) recognizes that community engagement plays different roles in the society:

- It allows citizens and communities to demonstrate their expectations, concerns, needs, and values, and - as the next step - they can influence policy development, decision-making, service, and product delivery at different levels and in different sectors.

- At the same time, community engagement allows policy makers, businesses, and nonprofit sector to involve citizens in decisionmaking and business processes.

The International Society of Sustainability Professionals underlines that "engagement is a means of achieving a number of objectives including involvement, cooperation, consent, control, risk management, shared value creation, and accountability" (ISSP-CSP 2017, 8).

Analyzing communities, it easy to recognize significant trends in their classification based on geography, interaction, and identity (Lee and Newby 1983). The variety makes identification of a community to engage with a somewhat complicated issue. Community members vary in engagement: from staying silent clients or customers of the energy-related services to being activists of some initiatives or nonprofit organizations. There are broad points around how to engage with communities (process) and what to engage on (content). Therefore, studies and surveys of customer's values, attitudes, and lifestyle choices should be reviewed.

The hierarchy of human needs proposed by the American scientist Abraham Maslow suggested that humans satisfy their most basic needs before they start looking for something else (Maslow 1998). Physiological needs were placed on the primary level. Those were followed by the need to have a shelter or a safe place to live. Care about health was recognized as a necessity only if these two first needs had been satisfied. The next steps may be love, belonging, and self-actualization.
The more customers earn, the more likely they perform environmentally friendly actions (Fisher et al. 2012).

This comprehensive chapter consists of four parts that take the reader on an interdisciplinary journey with examples from various geographic areas. One of the primary focuses is on customer engagement and behavior. This part reviews different stages of residential electricity use processes. Environmentally friendly customer behavior and lack of it are addressed more specifically from a North American perspective. A dedicated section provides suggestions on how to deal with the disengaged public. There are opportunities to discover similarities between community engagement and entertainment as well as to learn more about "ecotainment." Later, a reader evaluates the role of community organizations and youth activism and comes across six levels of personal engagement. The further parts address new challenges that include technology and the growing politicization of community relationships. The conclusion allows taking the final look on the community engagement issues raised in this chapter.

\section{Customer Engagement}

This volume of the encyclopedia is dedicated to affordable and clean energy. These energy characteristics contribute to a process of creating a specific image of energy in our mind, similar to branding. Furthermore, the word "affordable" underlines a commercial relationship with a price tag that is appropriate in this context since all of us pay at least for one type of energy. Purchase creates a customer relationship. Therefore, customers are the core group of any energy community and the primary group for community engagement.

Customer engagement is often a first step in community engagement. "Community engagement takes customer engagement and adds value by allowing customers to engage with one another," according to Daniel Newman (2017). 
Leading consulting firms publish reports about customer engagement in an era of energy transformation creating the particular chapters dedicated to the topic "Strategic context - why customer engagement is more important than ever" (PricewaterhouseCoopers 2016). This approach is popular among many energy-related organizations. The Ontario Energy Board (OEB) from Canada has developed the Consumer Engagement Framework. It is the "OEB's new, more comprehensive approach for engaging and empowering electricity and natural gas consumers throughout the OEB's decision-making process" (Ontario Energy Board 2016).

Customer behavior theory is based on the study of the processes of how individuals, groups, or organizations select, secure, use, and dispose of products, services, experiences, or ideas to satisfy their needs. The applications of customer behavior theory can be found in marketing strategy, public policy, and social marketing.

Customer behavior involves services and ideas, as well as tangible products. Some customers tend to adopt new products more quickly than others, based on several factors: modernity, homophily, physical distance, and opinion leadership. Scientists study the impacts which these processes have on customers and society (Calvert 2015; Byelyakov 2005). Customer behavior involves the use and disposal of products, as well as the study of how they are purchased.

Community needs and energy use vary in geographical, economical, and demographic contexts. Air conditioning is responsible for about $80 \%$ of energy use in Qatari residential buildings, the highest fraction in the world (Meier et al. 2013, 41). In Canadian households, heating contributes to over $60 \%$ of energy end use (Tardy and Lee 2019). Researchers identify energy poverty as a real issue in modern Canada: "high energy bills can lead to late or missed payments, leading to service disconnections (In 2015, 60,000 households were disconnected in the province of Ontario alone)" (Tardy and Lee 2019, 48).

In Ukraine, households face a lack of adequate domestic energy services (particularly space heating and cooling, lighting, as well as cooking) that contributes to the rise of domestic energy deprivation. The above-average rates of energy and fuel poverty affect especially older people, families with children, households with disabilities, long-term illness, or infirmity (Petrova et al. 2013, 1243). Unreliable electricity and power outages are common in post-Soviet states and South Asia (Zhang 2019). Sub-Saharan Africa has a limited access to electricity and household access to clean cooking fuels across the 31 countries reached only $10 \%$ (Armah et al. 2019).

In the developed world, research on customer behavior related to energy use mainly focuses on an increase in energy efficiency (either by choosing energy-efficient appliances, decreasing energy use, or changing particular use patterns) and chooses (where available and appropriate) energy products/services marketed as green ones (e.g., clean, renewable energy, certified green energy products, and so on). The next level of customer behavior would be their advocacy efforts to call for more green energy choices and sustainable lifestyles and respective policies and to educate others about such choices.

Customers, who are concerned about their energy use, are motivated by many factors: from a price of services to their knowledge about green choices, existing policies, and moral imperatives. Ideally, development of environmentally friendly customer behavior can influence the patterns of energy use.

This development has many stages. An academic community offers a variety of terms to describe such behavior: environmentally friendly, pro-environmental, more environmentally sound, environmentally significant, and some others (Gatersleben et al. 2002). While recognizing the variety of these terms, researchers should be using accurate terms. Ideally, they would be the popular ones also. Equally, public should be challenging terms which are vague or wrong or are misused often, such as green or natural.

Some behavioral change models describe the patterns of adaptation as a multistep process from habitual non-environmentally friendly customer behavior to environmentally friendly customer behavior (Dahlstrand and Biel 1997). Their research supports the hypothesis that general 
factors, such as environmental values and a sense of responsibility for the environment, are more influential in the early stages of changing established habits, such as purchasing energy-efficient light bulbs, than later ones. Furthermore, at a later phase of transition, specific beliefs about particular products will affect the testing and evaluation of new behavior (Dahlstrand and Biel 1997).

As a result, scientists emphasize the necessity to start environmental engagement much earlier in kindergarten. Childhood experiences in nature are among the most frequently mentioned factors that sensitize people's environmental awareness according to interviews of numerous professional environmentalists in the United States and in Norway (Chawla 1998). Expanding the opportunities for the younger generation to be involved in pro-environmental activities and exposing them to related ideas will have the long-lasting effects: "the most powerful long-term effects can be obtained by increasing the opportunities for children and young people to perform pro-environmental acts (e.g., cleaning up their neighborhood once a year) to establish past behaviors that would be difficult to ignore in adulthood" (Hamid and Cheng 1995, 695). Individuals who previously demonstrated an act of environmentally friendly behavior are likely to perform other environmentally friendly acts (Hamid and Cheng 1995, 694). Riemer et al. (2013, 7 ) also reported that "earlier engagement predicts future engagement."

A public that consists of the existing and potential green customers could play a significant role in the future promotion of environmentally friendly life choices, including in energy use. An engagement campaign can start with the dissemination of the green consumption concepts, which motivate an increase in the demand for services and goods that improve our health and contribute to the environmental protection. Energy efficiency can support the households and community resilience. Therefore, these topics should be reviewed in much broader context of discussion that is used to engage with communities.
Beyond the moral or "good citizen" arguments, there are real benefits to quality of life by improving resilience, by reducing energy use and switching to renewables. "Well-being, indoor comfort, property value increase, enhanced institutional relationships, competitive advantage on the market, and stimulation of the local labor market sound more interesting to different categories of stakeholders compared to greenhouse gas emission reduction and kilowatt-hours savings" (Bisello and Vettorato 2018, 486).

Communication with the general public should focus on the messages in layman's terms. Many consumers do not comprehend the juggling of the jargon and numbers. The lack of easily digestible learning in consumer education (especially microlearning) about energy issues affects community engagement.

People who demonstrate responsible environmentally friendly customer behavior over a broad range of problems already possess some knowledge of relevant environmental concepts and issues, as well as knowledge of action or strategies that may be used for solving these problems. They are also concerned about the quality of the environment, commitment to act, and believe that their action can make a difference (Howe and Disinger 1988).

A fascinating group is presented by workers from the developing countries who have spent time abroad and immigrants from the countries with the advanced environmental policies (Pfeffer et al. 2002, 64). They often follow the rules and expect standards that they experienced in other countries. Such individuals are more likely to be engaged in environmentally friendly customer behavior that is further on the green spectrum compared with the average person.

At the same time, a study conducted in Austria (Schwarzinger et al. 2018) found that the average person or in this case "average Austrians" as a relevant target group for communication do virtually not exist. Instead, the six Austrian "Energy Lifestyles" were identified based on the respondents' individual energy demand: "Mobile Performers," "Uncommitted," "Settled," "Educated Cosmopolitans," "Economically Restricted," and "Underprivileged." 
Scientists proposed to correlate the individual emission footprint with the "Paris Lifestyle," the benchmark of a lifestyle compatible with the goals of the Paris Agreement (Schwarzinger et al. 2018, 393).

Despite some pragmatism in consumption, more people are becoming concerned about their purchases of products or services. Additional attention to issues, such as energy use and sources, follows a new kind of consumption - guilt-free consumption (Trend Briefing 2013). At the same time, researchers recommend that "marketers positioning products through ethical attributes should subtly activate consumer self-accountability rather than using more explicit guilt appeals" (Peloza et al. 2013, 104).

There are new groups of environmentally conscious customers who do more research on alternatives. Their classification is broader than the classical behavioral segmentation by attitude toward a product. Traditionally consumers were divided into the following segments: an enthusiastic, positive, indifferent, negative, or hostile attitude toward a product (Kotler et al. 2019, 265).

There are different models to understand what motivates a target customer. One of them is VALS, or Values, Attitudes and Lifestyles, by Arnold Mitchell and others at the Stanford Research Institute (Yankelovich and Meer 2006). Consumers are divided in three main categories of psychographic methodology: need-directed, outer-directed, and inner-directed. Environmentally conscious customers have an additional classification: LOHAS (Lifestyles of Health and Sustainability) and LOVOS (Lifestyles of Voluntary Simplicity).

According to Mobium Group, an Australian LOHAS market research group, these customers fall into the specific market segments: leaders, leaning, learners, and laggards.

Leaders demonstrate strong concerns about personal, community, and planetary health and sustainability issues which shape their values, worldviews, and decision-making. Leaders are highly committed, knowledgeable and have high levels of current participation in multiple LOHAS market categories.
LOHAS customers in the leaning category have moderate to strong concerns regarding personal, community, and planetary health and sustainability issues. They currently participate in selected LOHAS market categories; however, they are not completely engaged and often make trade-offs in their consumption choices. Many feel highly conflicted by their desire to live a more sustainable lifestyle and maintain their current levels of material consumption.

Learners have more recent awareness of health and sustainability issues. They have poorer levels of knowledge and their interest at a community and planetary level is lower - they are more interested in personal aspects. They fundamentally want to do the right thing but are unsure where to start. At present they are not participating at any deep level in the LOHAS market categories.

Laggards have low levels of interest in the overall theme of health and sustainability in their lifestyles. Their future intention to participate in the LOHAS market categories is at very low levels (Mobium Group 2015).

Often environmental and health issues overlap (e.g., motivation in transitioning to a vegan lifestyle). In such cases, it is also beneficial to review the transtheoretical model about health behavior change. It includes six stages of change: precontemplation, contemplation, preparation, action, maintenance, and termination (Prochaska and Velicer 1997).

LOVOS customers are those who avoid consumption or restrict it to their basic needs. This group is somehow in dissonance with those seeking "the good life." Their motto is that many comforts in your life do not necessarily make you a better person (International Society of Sustainability Professionals 2017).

Arnold et al. (2018) confirm that "people's differences in their ecological lifestyles, manifest in their self-reported ecological behavior patterns, are substantially related to their actual electricity consumption." A study using the General Ecological Behavior scale discovered: "customers in a green electricity program reported more ecological engagement and consumed one third less electricity than did regular customers" (Arnold et al. 2018, 367). 
Changes in consciousness also depend on green services or products themselves. Some studies argue that the extent to which customers adopt green services or products is much lower than would be indicated by the opinion polls studying public attitudes toward environmentally friendly consumption. The 17-country study demonstrated the mixed results. Only $10 \%$ of Germans and $25 \%$ of Italians found green marketing strategies impressive. Almost $90 \%$ of consumers from Germany and France believe that companies support green initiatives to improve their branding, marketing, and sales. On an average, $24 \%$ of respondents around the globe acknowledged that companies' green marketing had a "significant or large influence" on their consumption. The majority did not donate to green organizations or organic gardening (TNS Global 2008). In another survey, 65\% of respondents said they want to buy purpose-driven brands that advocate sustainability, but only about $26 \%$ actually did so (White et al. 2019).

Scientists stress that there are several theories concerning the discrepancy between customers' environmental concerns and purchasing actions, which need further testing - there is a misspecification of green products in relation to customers' needs; there are barriers to perceptions of green products' environmental impact and customers' free ride due to individual self-interest (Wong et al. 1996).

Despite existing difficulties and need for improvements, experts are optimistic about the development of green consumerism. Scientists see a more efficient way to promote not only environmentally friendly customer behavior but eco-economic principles in general: "Building an eco-economy depends on a broad change in our public priorities and our private behavior, not only as customers but, more important, as eco-economy activists. People change their behavior because of new information or new experiences. Our goal is to realize the needed changes in the economy through providing new information, for if this fails, the inevitable adjustment could be painful" (Brown 2001, 259).

At the same time, adaptation of new information already caused overload, at least in developed countries. We have reams of data illustrating the extent of the impact of human behavior on the natural world. We also have long lists of mitigating technologies which could be deployed, but have not been. Therefore, recipients of new information should strive to transform it into new experiences more proactively. A focus on implementation and hands-on activities should be shifted especially in community work. Its priority is in the execution of the existing knowledge.

Promoting the economic and social benefits of community engagement is essential if political and financial support is to be forthcoming for environmentally related efforts. Some scientists (Tyson 2003) have already illustrated how to conduct campaigns to influence environmental behavior. Changes in public knowledge, attitudes, and behavior concerning environmental issues could be implemented with the support of communication campaigns.

Many organizations have the best practices. The Climate and Development Knowledge Network offered a well-structured strategy for energy efficiency campaign in India (CDKN 2015). Guidelines on creating an energy awareness program with a focus on behavioral change at work are provided by Eskom from South Africa (2015). The World Bank (2018) explains how to design communication campaigns for energy subsidy reform.

Lack of meaningful community engagement leads to disputes as wind energy projects demonstrated in Canada. Developers tend to treat minimum engagement requirements for local public meetings mostly as the maximum requirements and are reluctant to go beyond. There are observations in social science on public engagement from Canada, the United Kingdom, and Australia that legally mandated public engagement expectations tend to "create one-way information flow, which leads to 'tokenism' or even 'manipulation' rather than providing meaningful opportunity for public participation in decisions." (Fast et al. 2016, 5). Therefore, communities resist changes. A possible solution is encouraging the proper public's level of participation in any process based on the International Association for Public Participation's Spectrum: inform, consult, involve, collaborate, and empower (IAP2 2014). 
The International Association for Public Participation also states that engagement and public participation are essential components for achieving all 17 Sustainable Development Goals. At the same time, the lack of awareness about community engagement's importance in this process is noticeable enough to call for an International Year of Engagement and Public Participation (IAP2 Australasia 2016).

Environmentally friendly customer behavior has an excellent chance to be introduced as an advanced level of meeting human needs related to belonging, esteem, or self-actualization. The expected changes in behavior are slow and usually time-consuming. Academics, educators, and journalists can provide stronger support to speed up changes in attitudes. The media and schools are by far the most important sources of information about the pro-environmental behavior. The educated customers have the better understanding of why they should act in a specific way, such as to save energy.

Another level of environmentally friendly customer behavior could be achieved by the concept of "sustainable consumption" that benefits from the worldwide adaption thanks to its promotion by the United Nations. The 2030 Agenda for Sustainable Development helps to leverage insights about the 17 Sustainable Development Goals, 169 targets, and 232 indicators on which general agreement has been reached. These metrics help measure and facilitate change and embrace it using a global indicator framework for the Sustainable Development Goals and targets of the 2030 Agenda for Sustainable Development (United Nations 2019).

Goal 12 ensures sustainable consumption and production patterns and requires the national frameworks for sustainable consumption. The target 12.6 encourages companies, especially large and transnational, to adopt sustainable practices and to integrate sustainability information into their reporting cycle. The target 12.8 strives to ensure by 2030 that people everywhere have the relevant information and awareness for sustainable development and lifestyles in harmony with nature.
Goal 7 also offers support to ensure access to affordable, reliable, sustainable and modern energy for all. Sustainable consumption supports energy efficiency and should benefit from research into sustainable consumption patterns in energy use. While technological and interdisciplinary studies increasingly contribute to the field of energy efficiency and innovations around it, the choices of the energy users are still an overlooked area.

Allcott and Mullainathan $(2010,1204)$ confirm that "investment in scalable, non-price-based behavioral interventions and research may prove valuable in improving energy efficiency." Understanding behavioral factors that influence energy use and conservation is a focus of many studies (Pothitou et al. 2017; Elnakat et al. 2016; Zhou and Yang 2016; Calvert 2015; Lutzenhiser 1993, etc.). Our values contribute to household energy use and reflect the concept of quality of life (Poortinga et al. 2004). It would also be beneficial to analyze how sustainable consumption patterns in energy use, associated consumer behavior, and community engagement are emerging.

\section{North American Experience}

To succeed with community engagement strategies, governments recommend an increase in awareness regarding energy use, its reduction, and the use of social benchmarking (Ministry of Energy 2017). North American customers have one of the largest ecological footprints. Many US energy users do not plan to reduce their consumption and challenge this with concepts of modern convenience. The Rasmussen Reports summarize results of answers to a question: "Which is more important, finding new sources of energy or reducing the amount of energy Americans now consume?" (Dolliver 2009). It shows that $63 \%$ of respondents prefer to find new energy sources. Only 29\% care about reducing energy use (Dolliver 2009). The American dream has its materialistic roots and individualism also challenges community engagement.

As a result of such attitudes, the United States' place in the world ranking in energy efficiency was 13th. Canada was on the 9th spot. Both countries are less energy-efficient than China, 
which ranked the 4th. However, residential users are only a part of these developments because industrial customers are the largest contributors to these rankings. The energy intensity of China's industrial sector is the second highest of the world's 16 largest economies analyzed (Young et al. 2014, 3). In 2016, these rankings changed: the United States was \#8, Canada was \#10, and China was \#6 (Kallakuri et al. 2016). In 2018, China was \#8 and both the United States and Canada were \#10 (Castro-Alvarez et al. 2018).

The customer behavior survey about sustainable consumption in six major international markets confirms that renewable and alternative energy sources are among the most critical issues for businesses to address as part of their manufacturing, service, or operations for all six markets, according to $85 \%$ of respondents (Bemporad et al. 2012, 15).

More businesses realized the need for transformation. This is already confirmed by market research: "Owing to changes in the macro and microenvironments, corporate sustainability branding has become more important in recent years" (Belz and Peattie 2009, 186). At the same time, sustainability branding should be differentiated from greenwashing. There are some doubts that all organizations and businesses understand that they need to "walk the talk." Many businesses may have recognized the need to have the branding, but enacting the change in their corporate cultures may be a longer-term exercise. It should include the clear targets and ensure employee engagement. A better approach is to give value before businesses get value.

To understand the most efficient points of entry for community engagement, customer behavior should be reviewed on the different stages of residential electricity use processes: pre-purchase, purchase, use, and post-use. Research on community engagement does not equally cover all stages.

\section{Pre-purchase Stage}

How are customers acting during the pre-purchase stage? In many cases, customers show low engagement in this process. This can be explained by the lack of alternatives to major utility companies. In some cases, "many are skeptical of fashionably green claims made by big incumbent utilities" (Bloemers et al. 2001).

The Canadian company Bullfrog Power promises clean, pollution-free energy supply for residents in Toronto. At the same time, this innovative approach is not entirely convincing. Customers continue to receive a monthly bill from their current electricity provider, and Bullfrog sends a separate bill "for the additional cost of bullfrogpowering your home or business with green electricity" (Bullfrog Power 2018). If customers receive the same bill from Toronto Hydro, it is hard to convince them that their electricity becomes cleaner in comparison with the same energy mix they have had before.

Besides billing issues, there is another skepticism phenomenon of the sustainability liability or even "sustainability penalty" (Luchs et al. 2010). Customers ask the additional questions at community meetings tending to be suspicious that sustainable products underperform in some ways: they are not strong enough, provide less energy, and so on. Manufacturers can overcome the "sustainability penalty" through promoting effectiveness, strength, durability, and other strength-related attributes of their products or services. Most products and services offered to a regulated market must meet minimum performance criteria. Regulation in certifying products/ services as fit for purpose or drop-in replacements will be also helpful.

Marketing efforts and policies should be aimed at contributing toward sustainable consumption at all stages of energy use, educating customers, providing them with clear choices, and explaining the environmental implications of energy use. Specific approaches to community engagement can be used for different customer groups as described in customer behavior studies.

\section{Purchase Stage}

The purchase stage is the time of decision regarding application for the service and a first payment. The simplicity is appreciated; unnecessary bureaucracy concerns people. Consumers could also worry about the future bills - whether they will reflect the usage level and do not include hidden charges from the provider. 
Another issue of concern for users can be interpreting different lines in the energy bill and understanding why there could be seasonal variations and why the company might increase the rates. Consumers' education about environmentally friendly services and energy-saving products should include persuasive comparison of their benefits among others choices.

OECD/IEA report $(2018,45-46)$ found that "consumer preferences are driven by a number of different concerns, including the upfront cost of buying the equipment and the cost of running it. Unsurprisingly, consumers - be they households or businesses - are less concerned about buying an efficient unit and using it efficiently if electricity is subsidised, which is often the case in the emerging economies. As the most efficient devices tend to be more expensive (in part because of pricing strategies or because they incorporate additional features), consumers may decide not to purchase the more efficient equipment, even if the energy cost savings would ultimately make up for the additional upfront cost."

Lack of consumers' environmental awareness could be a culprit of increasing climate change. There are consequences of not buying the most energy-efficient air conditioners. Together with electric fans, they account for nearly $20 \%$ of the total electricity used worldwide in buildings. Fatih Birol, Executive Director, International Energy Agency, believes: "The growth in global demand for space cooling is such a blind spot: it is one of the most critical yet often overlooked energy issues of our time. If left unchecked, energy demand from air conditioners will more than triple by 2050 , equal to China's electricity demand today." (OECD/IEA 2018, 3).

\section{Use Stage}

The use stage for electricity is significant regarding the following questions related to customer behavior:

- How much do customers use, and what are their current use patterns? Are they aware of their usage level and seasonal use patterns?
- Are they interested in decreasing their consumption and making their households more energy-efficient?

The Harris Decima company conducted a customer segmentation study on the updated residential profile sponsored by the Ontario Power Authority (OPA) in 2011 in Canada. A survey of over 3,000 Ontarians showed that customers became more knowledgeable about energy conservation compared to a similar study in 2007 (Meloche 2012). Residential customers' behavior regarding electricity conservation is critical for community engagement. Customers can be categorized as:

- Generally engaged

- Supportive, but not proactive

- Not engaged but with a willingness to became more involved

- Not engaged overall but with specific potential points of curiosity

The researchers have discovered the following consumer segments (Meloche 2012): Bea Lever, "Conservation Collaborator"; EarthaSustain, "Conservation Craver"; Flo Gowith, "Fence Sitter"; Simon Sayuz, "Conservation-Challenged"; Don Wanna, a "Hard Target" (see Table 1).

According to this study (Meloche 2012), immigrants to Canada make up one-third of the segment of the population in Ontario that is very concerned about electricity consumption and its impact on the environment, resulting in much more conservative use and more interest in community engagement meetings on energy-saving topics. The study refers to this group the "Conservation Cravers," and they are the second only to the "Conservation Collaborators" (a slightly "greener" category of Ontarians) in their demonstrated environmental stewardship.

Many organizations successfully focus on immigrants to Canada in their community engagement. The Mount Dennis Community Association (MDCA) works in one of the most diverse neighborhoods in Toronto. MDCA was 


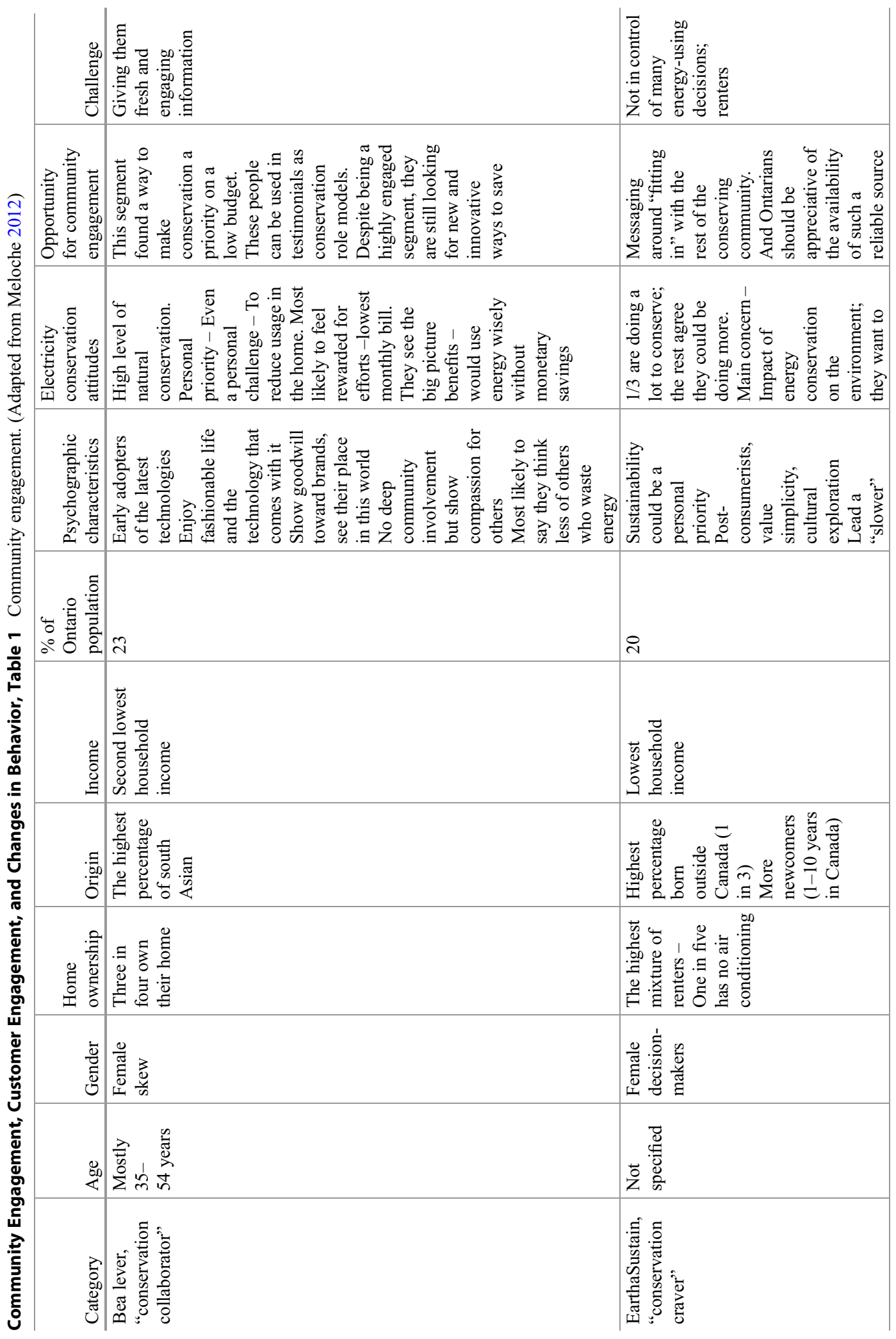




\begin{tabular}{|c|c|}
\hline & 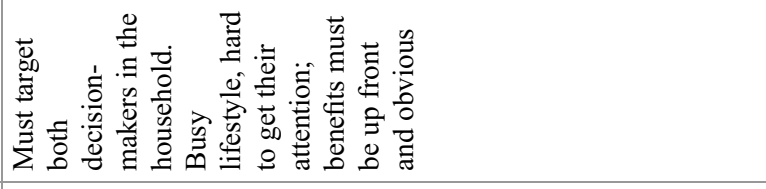 \\
\hline 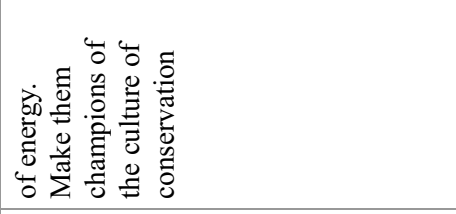 & 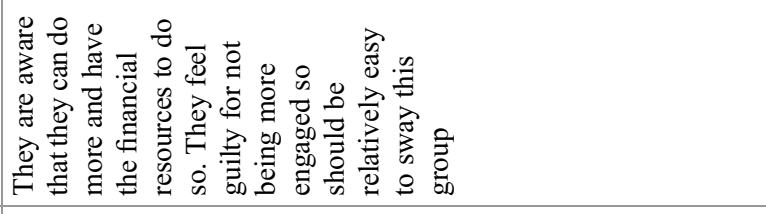 \\
\hline 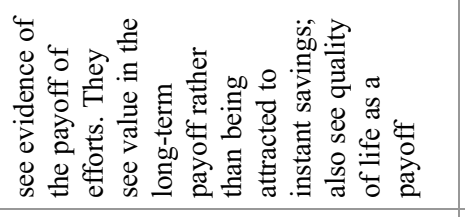 & 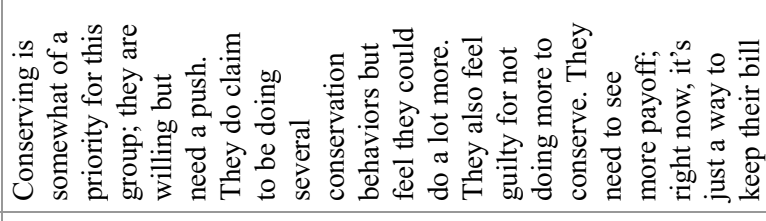 \\
\hline \multirow[t]{8}{*}{ 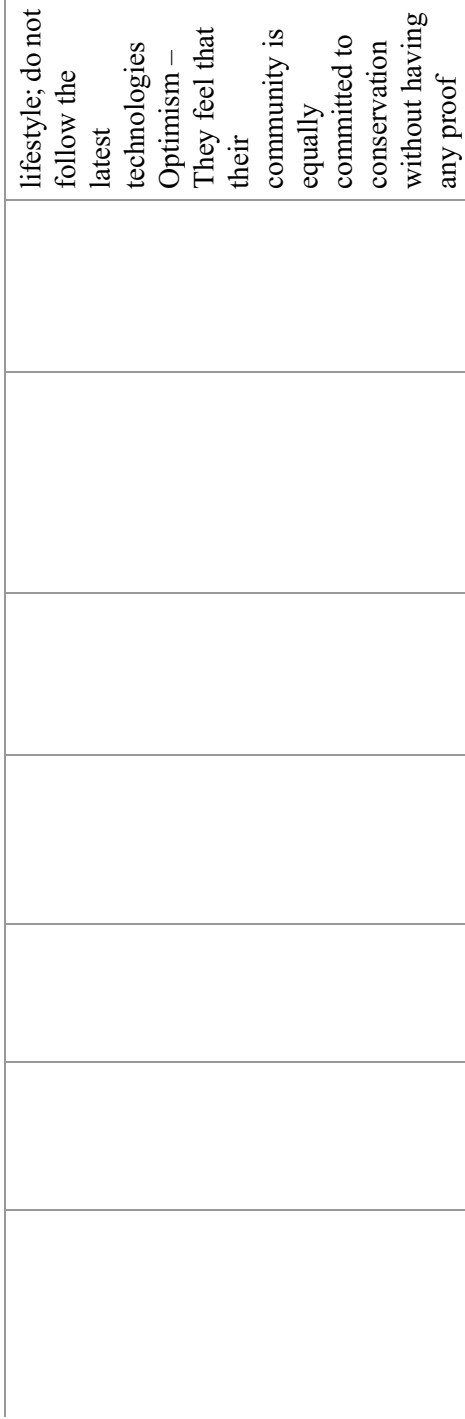 } & 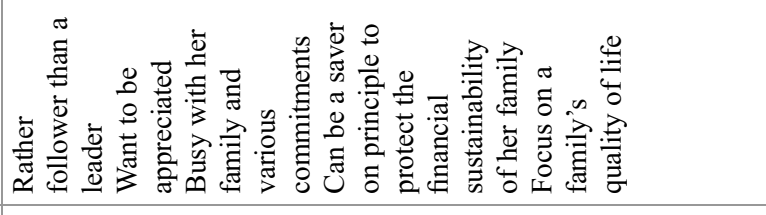 \\
\hline & 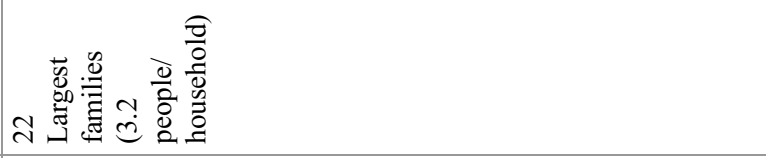 \\
\hline & 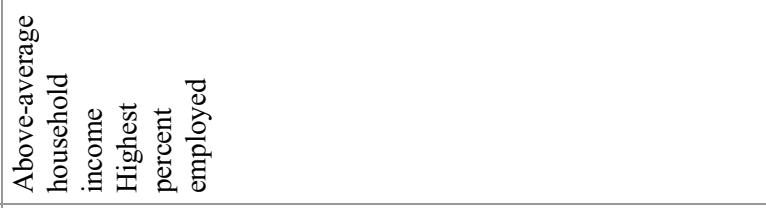 \\
\hline & 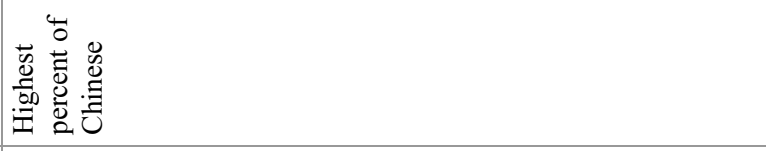 \\
\hline & 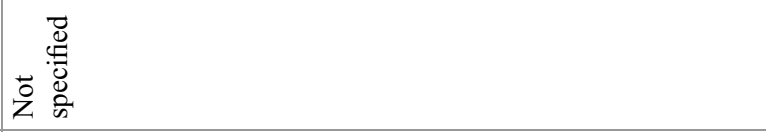 \\
\hline & 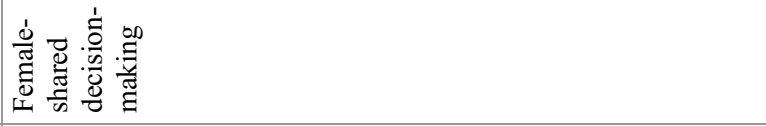 \\
\hline & 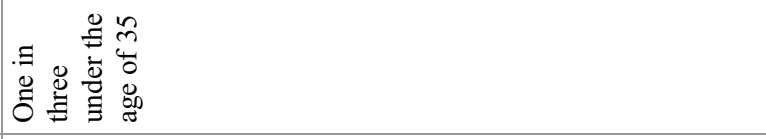 \\
\hline & 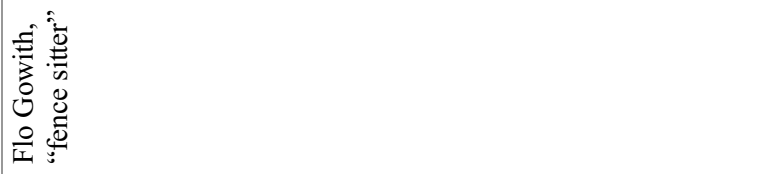 \\
\hline
\end{tabular}




\begin{tabular}{|c|c|c|c|}
\hline 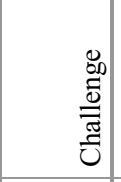 & & 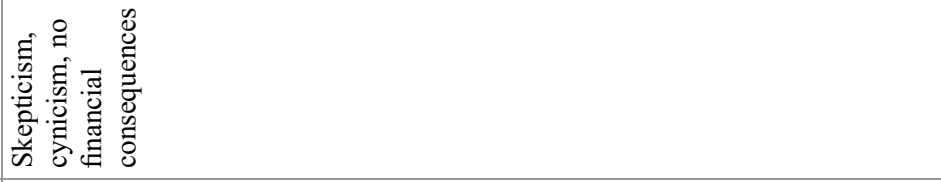 & 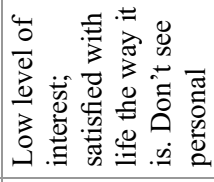 \\
\hline 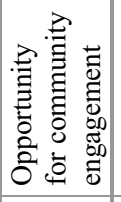 & & 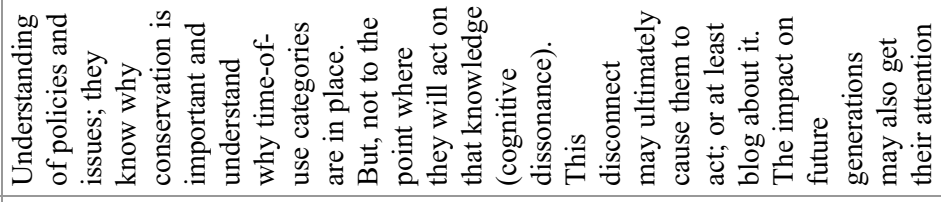 & 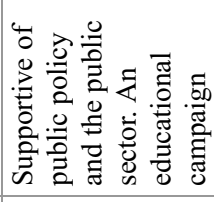 \\
\hline 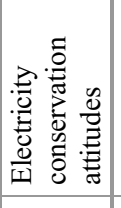 & 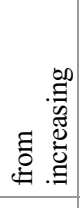 & 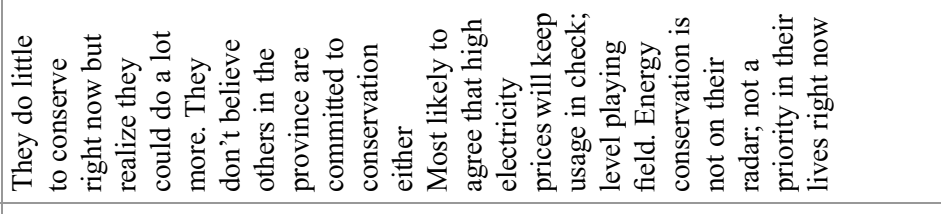 & 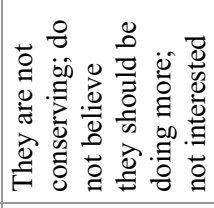 \\
\hline 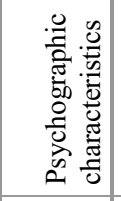 & & 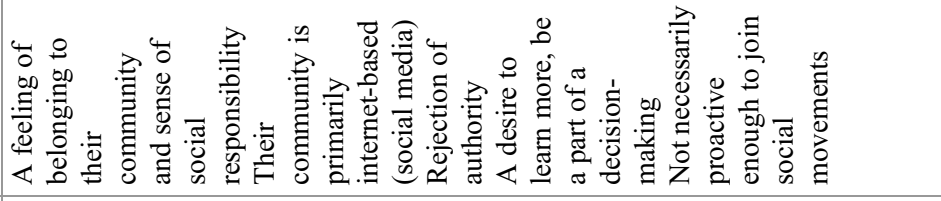 & 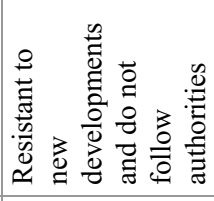 \\
\hline 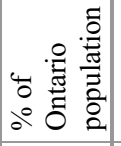 & & 2 & 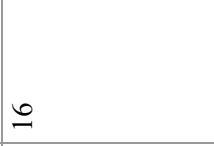 \\
\hline 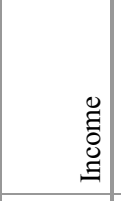 & & 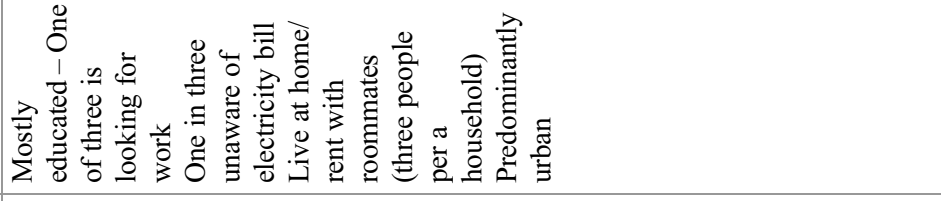 & 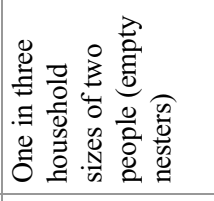 \\
\hline .5 & & 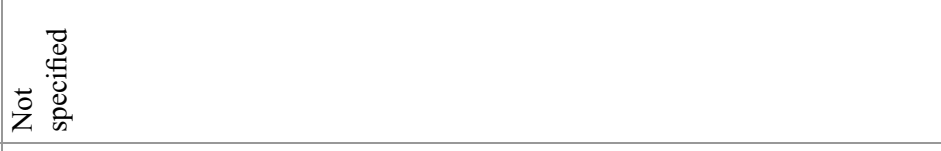 & 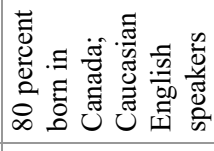 \\
\hline 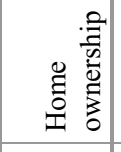 & & 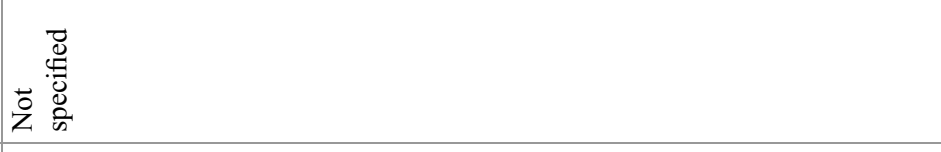 & 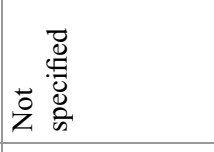 \\
\hline $\begin{array}{l}\overrightarrow{\bar{v}} \\
\overrightarrow{0} \\
0 \\
0\end{array}$ & & 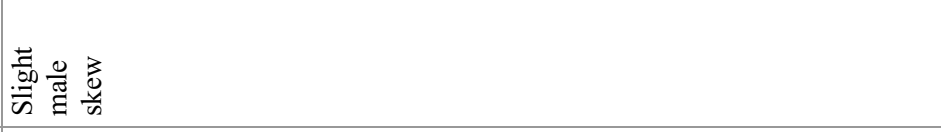 & 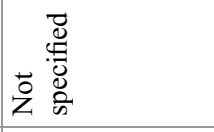 \\
\hline$\underset{8}{8}$ & & 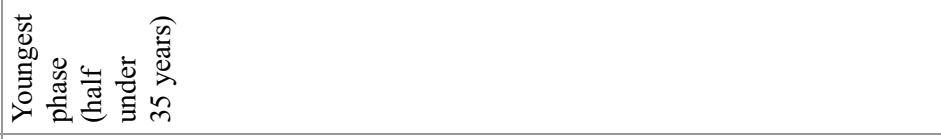 & 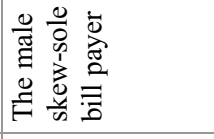 \\
\hline 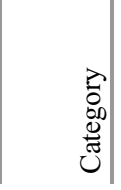 & & 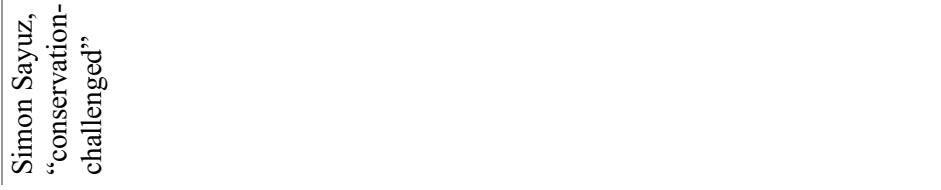 & 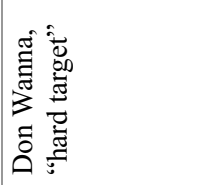 \\
\hline
\end{tabular}




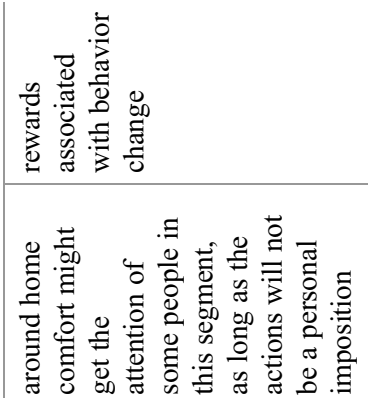

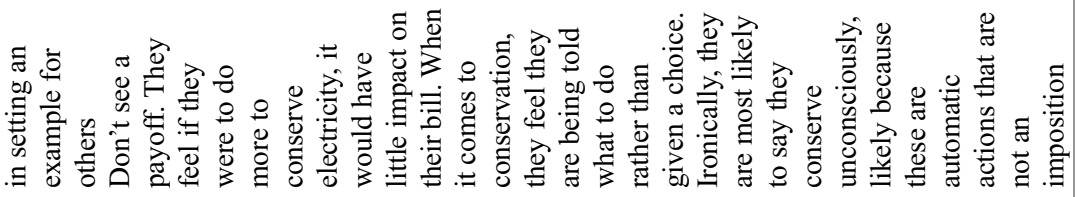

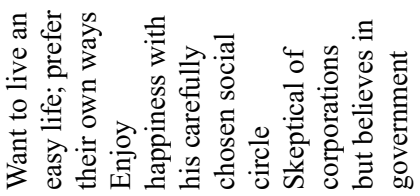


nominated for the Ontario Sustainable Energy Association award for community participation in sustainable energy.

Electricity use, awareness, and community engagement can vary among customers. Some are just paying their bills without being cognizant of the usage; others show some degree of interest depending on their financial situation, personal belief, or participation in social movements. There are differences according to gender and income (Oswald et al. 2020). This data confirms observations that "pro-environmental behavior is more strongly related to attitudinal variables, whereas household energy use is primarily related to variables such as income and household size" (Gatersleben et al. 2002). Behavioral changes take time because "old habits form a very strong barrier that is often overlooked in the literature on pro-environmental behavior." (Kollmuss and Agyeman 2002, 257).

\section{Post-use Stage}

After purchasing electricity, customers can compare their expectations and actual experiences. They reflect on their satisfaction or dissatisfaction that influences decisions to buy from the same organization. After studying their past consumption patterns, customers may decide to:

- Cut electricity use per month or within a specific period (e.g., reducing more during summer when bills can become higher with the use of air conditioners)

- Change their patterns of use (e.g., do laundry during off-peak hours)

- Learn more about sources of energy that the utility company sells, billing, how much other people use and about increasing energy efficiency

- Advocate for some changes in public policies related to residential electricity.

The theory of cognitive dissonance often addresses the post-use stage. According to this theory, individuals strive to have consistency in their lives. If beliefs and behaviors start to contradict each other, it causes discomfort or even stress. Cognitive dissonance cases are especially known after nuclear disasters (Belyakov 2015). Customers were informed that nuclear energy was safe, but increased radiation levels and contamination affected their health.

In Canada, the City of Toronto, the Region of Durham, and Ontario Power Generation are mailing potassium iodide (KI) to homes and businesses within the $10 \mathrm{~km}$ zones (Canadian Nuclear Safety Commission 2019). They are also supplying KI pills on request to all residents living within $50 \mathrm{~km}$ of the Pickering nuclear plant. At the same time, this case demonstrates low support for community engagement; authorities provide insufficient explanations why they are doing these mailings right now. Believing that residents of the potentially affected areas will do their homework, officials leave customers alone with explicit assumptions, hard-to-make decisions, and actions that could influence their behavior. Toronto's public school board is urging officials to provide schools within $50 \mathrm{~km}$ of the Pickering nuclear plant with a supply of anti-radiation pills in case of an incident (Rushowy 2018). This request resonates in local communities.

Ontario Power Generation reported receiving between 100 and 200 orders each month. At the same time, 32,388 KI pill orders were placed just in 2 days following a false nuclear emergency alert. A broadcast-intrusive message was sent to cellphones, TVs, and radios across the province on January 12, 2020 (Durham Radio News 2020). Canada's National Public Alerting System issued a second alert only $108 \mathrm{~min}$ later, advising that the previous alert had been sent in error. The conducted investigation revealed communication failures, significant concern, "alert fatigue," and confusion in communications to the public (Ministry of the Solicitor General 2020).

Authorities often repeat a typical mistake that some experts even refer to as the single biggest problem in communication. This is the illusion that communication has taken place (Whyte 1950). Communication should improve and be used especially for behavior-focused programs in the residential sector. Changes in consumer behavior are more cost-effective comparing to 
technology-oriented demand side management measures.

The power of social comparisons when customers match their own experiences to those of their community was used in the United States. A company Opower sent "home energy-use reports to electricity and gas consumers that display the household's energy consumption, compare it with that of similar households, and provide energy conservation tips" (Allcott and Mullainathan 2010, 1204). Such initiatives reduced energy consumption at least by $2 \%$ and did not increase energy use in household savers.

This is an exciting approach in community work that requires significant planning and understanding of all kinds of attitudes. Practitioners need to think twice through potential consequences, especially the unintended ones: what is going to change that you may not want to change as a result of letter distribution or use of various channels. Do they expect to achieve more cooperation or competition in a local community (keeping up with Jones)? Are energy providers distributing these leaflets in an effort to encourage less energy use or to motivate households to switch energy companies?

At the same time, we should remember that residential energy use is different from commercial and industrial, as well as from transportation energy use. These sectors consume a different percentage of energy depending on the country's development priorities and local incentive policies.

\section{Dealing with Disengaged Public}

The community engagement levels vary across different factors (agenda in developed and developing world, demographics, educational levels, and so on). Stressing a role of the future generations in sustainable development, researchers are concern about the disconnections that hinder youth engagement, addressing ineffective communication and collaboration. There is another issue: “today's youth are less accepting of hierarchical structure compared to previous generations and they expect active participation in leadership roles in order to feel motivated to engage in the activity or programme" (Riemer et al. 2013, 7). Scientists also discover that positive learning experiences and early successes keep young people engaged.

In India, women villagers once rejected innovations. The dedicated community engagement facilitators encouraged dialogue on value, purpose, will, and integrity. Finally, women learned more about innovations, became vocal members of their communities, and were even involved in entrepreneurship (Wilson 2019).

Andragogy, as the art and science of adult learning, can be used as a general practical framework dealing with disengaged public. In his works (Henry 2011), Malcolm Shepherd Knowles suggested four principles community facilitators and educators can apply choosing adult learning techniques:

- Adults should participate in the planning and evaluation of their learning, which can be done through needs assessment and review of previous evaluations.

- Experience (including mistakes) serves as the basis for the learning.

- Adults are most interested in learning subjects that have immediate relevance and practical applicability.

- Adult learning should be seen as problembased rather than content-based. This means tasks for active learning exercises should be very practical and job-related.

Breaking down complex innovative or technical ideas to very diverse participants like women in rural India can be challenging. Educators should use opportunities for in-person interaction and focus on the most important information, language for more everyday conversation, and appropriate context. A regular feedback helps educators to be on their way to getting community members on the same page as their facilitators' team. Adult learning techniques will help to promote active engagement, collaboration, sharing of ideas, critical thinking, and development of other transferable skills. 
The popularization of recent initiatives such as Sustainable Development Goals introduces them to broader audiences. It allows remedying the existing crisis of international organizations making their work more understandable for people from all walks of life. Making community engagement entertaining could contribute to some extent to active citizenship. Even debates between energy experts are expected to be as entertaining as show or sports events. In this case, messages may become accessible to comprehend for a mass audience.

At the same time, a decrease in community engagement is related to many factors. Besides lack of time for active participation in many initiatives, there is a competition with many other interests and activities, including leisure activities and entertainment media consumption. Entertainment media started to play an enormous role in communication with the disinterested public. Entertainment and social media, capitalizing on direct connection to our mobiles, should be used to re-engage audiences for educational purposes (videos and online courses), inquiries, surveys, fundraising, advocacy for policy change, signing e-petitions, and so on.

Celebrities like Leonardo DiCaprio use Instagram and other networks to mobilize individuals for climate change actions. At the same time, such online engagement sometimes results in an illusion that "likes" have a meaningful impact on the problem and leads instead to a couch potato activism. Hodson et al. (2017) describe this process as "slacktivism": the tendency of social media to encourage virtual posting about an issue, without a proper action in real life.

Community engagement and entertainment, coincidentally or not, have some similarities. Both are operating in the same public field. As a result, the place where community engagement approaches entertainment and entertainment is interacting in community engagement has become a new point of contact that needs definition.

Ecotainment is an already existing term created as neologism with using amalgamation for describing studied processes (Lichtl 1999). "Ecology" and "entertainment" are committed to each other. The child of this partnership was already known as "Ecotainment." Of course, for many people, consumption of entertainment media is not associated with improving knowledge about affordable and clean energy. However, learning could be a valuable by-product. Just one example, Creative Dynamo Ecotainment from the United Kingdom, offers many things: from mobile eco-disco to wheelbarrow disco with upcycling, solar cooking, and screening films in a solar cinema (Creative Dynamo n.d.).

Other types of ecotainment are gamification and street art. This is an application of game design elements in various non-game contexts. AlSkaif et al. (2018) found in their research that "gamification is a key component for driving customers' energy-related behavioral change and increasing their participation." This approach is demographic-specific in the same way as some other ecotainment innovations. For the visibility of the issues, cities and businesses can use street art and murals. Such murals addressed the goal of affordable and clean energy in Turin, Italy (Bergen 2019).

Ecotainment needs to scale up to meet the needs of larger populations. As an example, huge potential of viewers' engagement is yet to be discovered by Hollywood. In 2019, the International Movie Data Base ranked the miniseries Chernobyl higher than Game of Thrones. A byproduct of an access to a such broad audience is public awareness about nuclear energy issues. Greatly navigated the complexities of nuclear power, actors offered us added value in disaster management and organizational management of a nuclear power plant. In some cases, pseudodocumentarism went too far. The producers miscommunicated some technicalities of why the disaster happened, the immediate health consequences of radioactive contamination (too much blood), and other things. Nevertheless, such films could help to wake interest in reading academic books about Chernobyl, encourage visits to the $30-\mathrm{km}$ zone, and promote science and studies of the consequences of radioactive contamination (Belyakov 2019). 


\section{Role of Community Organizations}

In some cases, community engagement is done with the help of community organizations that "are becoming an increasingly vital locus of action and citizen engagement" (Case and Zeglen $2018,185)$. There are different frameworks applicable to this type of work, but priority should be given to the time-proven ideas from the fields of community. Gideon Rosenblatt from the Groundwire, an organization that focuses on how to engage and mobilize people, developed the Engagement Pyramid (Rosenblatt 2010). Many nonprofit organizations, including Greenpeace (Mobilisation Lab 2015), are using its integrated approach to spanning engagement in both Internet-based and face-to-face communications. The Ladder of Engagement has six levels of personal engagement, in which a person:

1. Is interested in a cause and aware of an organization, learning more via friends, media, social media, websites, and attending events

2. Agrees to receive info, provides contact information, or subscribes

3. Takes single-step or straightforward actions with low risk/investment, signs petition, makes a one-time/small donation, and shares content

4. Makes multistep assignments/actions representing a significant contribution of time, money, or social capital, joins groups, and attends gatherings

5. Promotes ongoing, collaborative actions: major investments of time, money, and social capital often blur

6. Leads others, engaged becomes the engager, focuses on training others, get easily confused with staff

Some people in communities are either not engaged or actively disengaged. While the theory of community engagement explains some straightforward stages, a practice of their development could be challenging. Robinson et al. (2019) confirm that human behavior is hardly predictable as multiple constraints stop individuals (with consequences for a whole community) from behaving in agreement with their beliefs and attitudes. Therefore, a focus on understanding behavioral intention instead of actual behavior is used in many models. As a result, uncertainty may arise in decision-making and predicting behaviors. This might appear as partial controllability - the contrast between the intended and realized implementation of the planned activities. These phenomena may be misunderstood or overlooked by community engagement teams. In practical terms, failure to account for partial controllability could lead to the choice of suboptimal actions. One of the practical conclusions from these theories and modeling is the need to have several modes of actions if behaviors of involved parties differ from the expected scenario. It is beneficial to learn from various case studies.

Let us review one of them. The Roots Collaborative (TRC), a not-for-profit cooperative from Toronto, Canada, completed the Home Energy Savings Initiative (HESI). According to Halyna Zalucky, the founder, the project aimed to educate homeowners about opportunities to decrease energy use at their home, thereby reducing their carbon footprint and cost and improving comfort (Zalucky 2019). Methods used to engage the community included presentations made in public spaces - libraries and community centers - and in peoples' homes. The team vended at a number of community events to raise awareness about different energy-saving incentive programs that were available at the time through governmentand utility-sponsored programs. An extensive social media campaign was also launched which included a webinar and video, which shared "doit-yourself" (or DIY) tips on how homeowners and renters could reduce energy use in their homes to save money and minimize their carbon footprints.

The social media campaign proved to be tremendously successful. Through the various platforms used (Facebook, Twitter, and Instagram), over 32,000 people were reached. The DIY video alone was viewed by over 5,000 people. On the other hand, in-person attendance at the public events was fairly low, averaging around 5-10 people. The HESI team felt that a major factor of the low attendance is the competing priorities that 
people have in their daily lives which make it difficult to find time and energy for such engagements. Furthermore, the "ask" to have people host a presentation in their homes may be imposing for many, who may feel apprehensive of others being in their home for a variety of reasons, such as shame around living conditions, the burden of hosting, safety concerns, and so on. Additionally, the team faced the challenge of coming in as an outside group and the time and energy it took to build trust within the community. Finally, TRC efforts were limited by constraints of time and resources, which is a common challenge among nonprofit organizations.

The project leader explains: "Whenever I think about my experiences with community engagement, I am always overwhelmed by a feeling of excitement - how great it is to get to know and help activate a community - followed by pangs of panic. The panic results from the multiple flashbacks I get of those stressful moments where community engagement reveals itself in all its complexity. What makes it complex? There are a variety of factors: What is the relationship between the engager and the community being engaged? Coming in cold, without any prior relationship is never easy. It takes time to develop trust. Communities are furthermore comprised of diverse members with diverse perspectives and opinions. Finding common ground can be challenging. Further, issues arise when expectations are created and not met. Perhaps objectives were not clearly laid out, to begin with, which may cause problems down the road" (Zalucky 2019).

Nonetheless, engaging a community, as was experienced through HESI, can be extremely rewarding. When people are inspired and empowered to take on work that will improve their lives, tremendous satisfaction can be reaped by the individuals and organizations that helped to make it happen. Efforts are further sustained within a community if its members played an active role in shaping and enacting the changes made. When TRC engaged a community, they were not providing solutions; they were helping to enable those solutions within a community.
In this sense, the hard work is well worth the effort and can have lasting effects.

Engaged communities are expected to take part in such initiatives as the Home Energy Loan Program (HELP) in Canada. Toronto City Council encourages homeowners to apply for a low-interest loan of up to CAD $\$ 75,000$ to cover the cost of home energy retrofits (energy storage technologies like batteries, electric vehicle chargers (Type 2+), as well as a broad range of existing measures, including solar PV systems, energyefficient windows, insulation, and more).

There are some cases when community should consider involving a nonprofit organization or even create its own. A formal legal structure is highly beneficial for fundraising and scaling up processes, especially for the projects meeting the needs of large (up the international) communities.

Liter of Light is one of the successful global, grassroots movements that aim to ensure affordable, sustainable solar light to people in energy poverty. In 2002, the Brazilian mechanic Alfredo Moser had a light-bulb moment after frequent electricity blackouts. His invention is simple: plastic bottles full of water and bleach (to prevent algae from growing in that water) are inserted into a hole made in the roof of the building to provide the equivalent of a 55-Watt bulb during the day.

Illac Angelo Diaz, a social entrepreneur from Philippines, established a charitable organization to help people with limited or no access to electricity. Liter of Light scaled up the original idea to build solar night lights by adding a micro solar panel in these plastic bottles. The main offices are in the Philippines, the United States, and Colombia. Women's cooperatives now operate building solar night lights in the Philippines, India, Bangladesh, Pakistan, and Colombia. Liter of Light has already helped 145,200 households in the Philippines and 353,600 homes in over 15 countries. The Office of the United Nations High Commissioner for Refugees adopted this open-source technology for use in some camps (Liter of Light 2019).

Tripti Aggarwal, a social entrepreneur from India, noticed why it is easy to empower communities with this project: "through light you are 
making a long-term impact, yet the beneficiaries are not dependent on you. It's a very small exchange that happens" (Anand 2018).

\section{New Challenges}

Growing politicization of community relationships affects community engagement, transforming it into activism. Therefore, autocratic governments around the globe want to silence critical voices and view some meetings with a local community as suspicious. The top-down, bureaucracy-driven institutions face issues with a community-driven approach.

A key challenge in community engagement practice is understanding how to develop community engagement projects to promote authentic and representative community participation and voice. An authenticity matrix helps practitioners in assessment and critique of their past and current projects (Johnston and Lane 2019).

Another challenge in community engagement is a relationship between the political agenda and themes that are discussed with a broad public. Experts (do Paço et al. 2009) describe that environmental issues considered to be a part of a "liberal" political agenda. As a result, individuals with more conservative political views and especially politicians may feel threatened to support the environment as a cause or political choice. Capella (2016) observed, "that the power of keeping a subject off the agenda or that is, denying access to an issue is as important as the power of placing it on the agenda."

Climate change is one of the complex issues for engagement. "You would think the media and every one of our leaders would be talking about nothing else, but they never even mention it," believed Greta Thunberg, an activist from Sweden. The teen activists (who skipped school to protest gun violence at Parkland in Florida, USA, in 2018) inspired Thunberg to do the same for the climate. She was able to engage the community while on strike outside of Swedish parliament during school time every single Friday for the 30 weeks. Greta gained international attention on social media and started the school strike for climate.
The Organization of the Petroleum Exporting Countries (OPEC) declared Greta Thunberg, as well as the other young activists, the "greatest threat" to the fossil fuel industry. "And that they see us as a threat because we are having an impact," responded Greta (Thunberg 2019). She criticized politicians for ignorance of science and lack of real sense of urgency. Thunberg branded the European Union legislation to tackle climate change as a "surrender" and offered another way: "We simply need to change our behaviour, our society" (Bock 2020).

Thunberg has been named "Time" magazine's Person of the Year for 2019. As of 4 March 2020, the "Fridays for Future" movement claimed to involve 13 million strikers during 103,000 strike events in 7,500 cities of 228 countries (Fridays for Future 2019). These youth actions are close in tactics to civil resistance: nonviolent protest and persuasion, noncooperation (social, economic, political), and nonviolent interventions, such as strikes, boycotts, marches, slowdowns, and stay-aways (Belyakov 2016).

Extinction Rebellion (XR) is an international movement that addresses climate emergency, biodiversity loss, and ecological justice. XR was established in the United Kingdom in May 2018. XR's founder Roger Hallam found that "extensive campaigns of large-scale nonviolent direct action" are factors critical to the success of the engagement. Hallam also reported that "meaning and happiness - a sense of wholeness and calm come from engaging with others as a community in making the world a better place." (Hallam 2019). Breast- and bottle-feeding mothers blockaded the headquarters of five major parties before the UK General Election (Extinction Rebellion 2019). XR occupied prominent sites, the London Stock Exchange and governmental and media offices, including the British Broadcasting Corporation requesting "to shift its policy and play a vital role in facing up to the ecological crisis" (Clifton 2018).

Sophia Geiger, the 17-year-old climate activist, wrote on her Twitter site: "Imagine if the media reported on the climate crisis like it does on the coronavirus. Headline news every day, constantly releasing an updated death toll, analyzing whether world leaders are doing enough, most importantly, 
making public believe this is something to take seriously" (Geiger 2020).

While environmentalists will be happy with such increased media attention to climate change, there are many risks of distributing an excessive amount of information about any problem. This process is also known as infodemics. Information overload makes it difficult to identify a solution. More hype and fear on social media is not always beneficial for decision-making and our mental health.

The role of technology is growing in our daily lives. Community engagement should also explore artificial intelligence and opportunities provided by high-tech solutions. Breaking stereotypes is possible even for such "old school" actions as the tree planting. BioCarbon Engineering from the United Kingdom uses drones and repurposed military technology. This tree-planting drone company works with local nongovernmental organizations and women farmers in Myanmar. The firing drones take the place of tractors - "sky tractors" - as Irina Fedorenko, a co-founder of the company, refers to them. People can plant trees 60 times faster, by shooting seedpods into ground while using artificial intelligence and various sensors. Such actions can help deepen the community's engagement while producing fast results (Stone 2017).

Our modern world has an increasingly digital nature. The new ways of engagement and additional education are required for the newly emerging or prospective communities. Some people increased energy consumption in their households following hype in cryptocurrencies mining. Back in 2009, bitcoin enthusiasts could mine with their desktop or laptop computers from their bedroom. After the price of bitcoin climbed to nearly $\$ 20,000$ in 2017 , the industry became highly competitive. Li et al. (2019) describe mining as the process when "transactions are verified and added to the blockchain. The devices conducting the calculation are miners." Experts are warning that "the computer power needed to create each digital token consumes at least as much electricity as the average American household burns through in two years" (Popper 2018).
Truby $(2018,399)$ takes this discussion to the next level: "Bitcoin mining and transactions are an application of Blockchain technology employing an inefficient use of scarce energy resources for a financial activity at a point in human development where world governments are scrambling to reduce energy consumption through their Paris Agreement climate change commitments and beyond to mitigate future climate change implications." Truby believes in "registration fees on ownership that differentiate in cost based upon energy consumption of the Blockchain technology" $(2018,410)$. According to Bitcoin Energy Consumption Index (2019), "bitcoin is extremely more energy intensive per transaction than VISA."

Responding to the latest developments, practitioners (like Gus Speth, a US advisor on climate change) and academics believe that we need to rethink the emerging global issues. "The real environmental problems are selfishness, greed, violence, apathy, and lack of awareness which are playing havoc with the integrity of our planet" (Dhiman 2018). These behaviors should find a designated area for the future research in sustainable consumption, environmental psychology, environmental ethics, and other interdisciplinary studies linked to energy use. Scientists and practitioners need to respond to the constantly changing world and energy issues and support "the strategic leadership environment in terms of volatility, uncertainty, complexity and ambiguity" (Mackey 1992).

\section{Conclusions}

To properly ensure community engagement, it is essential to learn more about communities, discover resistance points early, and use every opportunity to address them. Another critical task is the identification of advocates and adversaries to involve them in the process (from community organizations to individuals). One more priority goal is to promote cooperation across geographical borders (district, municipality, province/state or country), various sectors, and institutions ranging from the government to front end staff. 
Lifelong learning and dialogue on community values and needs play an important role. An additional challenge may arise while dealing with the interdisciplinary nature of some initiatives, such as Sustainable Development Goals. Success here requires the involvement of experts and practitioners from different fields, as well as multiple stakeholders.

Customers are the core group of any energy community. Under such conditions, customer engagement creates a necessary basis for further community engagement. Studying the customer behavior and consumer segments as well as recognizing their role in community engagement is essential in action planning. Implications of customer behavior vary based on geographical, social, and economic factors. Customer behavior surveys play an important role in identifying the recent trends in sustainable energy use of households and different types of behavior. A stronger research response to emerging challenges (growing politicization of community relationships, activism), changing behaviors trends (ecotainment), and new technologies (artificial intelligence, cryptocurrencies mining) is needed.

Nonprofit community organizations are beneficial partners in community engagement, especially in the multiethnic environment. When some organizations engage a community, their aim is not to provide solutions; instead, they help to enable those solutions from within a community. Nonviolent environmental movements are increasingly engaging communities worldwide.

\section{Cross-References}

- Consumer Behavior in Buildings Energy Use

- Corporate Social Responsibility

- Energy Consumption: Strategies to Foster Sustainable Energy Consumption

$\checkmark$ Promoting Policies

\section{References}

Allcott H, Mullainathan S (2010) Behavior and energy policy. Science 327(5970):1204-1205

AlSkaif et al (2018) Gamification-based framework for engagement of residential customers in energy applications. Energy Res Soc Sci 44:187-195. https:// www.sciencedirect.com/science/article/pii/ S2214629618304420. Accessed 6 Mar 2020

Anand R (2018) Interview with Pankaj Dixit, Liter of Light Banglore. The IndianPreneur. November 29. http://theindianpreneur.com/pankaj-dixit/. Accessed 5 Mar 2020

Armah FA et al (2019) Predictive probabilities of access to clean cooking: evidence from the demographic and health surveys in 31 countries in sub-Saharan Africa. Environ Just 12:3

Arnold $\mathrm{O}$ et al (2018) Capturing the environmental impact of individual lifestyles: evidence of the criterion validity of the general ecological behavior scale. Environ Behav 50(3):350-337

Belyakov A (2015) From Chernobyl to Fukushima: an interdisciplinary framework for managing and communicating food security risks after nuclear plant accidents. J Environ Stud Sci 5:404

Belyakov A (2016) Is Civil Resistance a Panacea to Modern Conflicts? Peace Magazine Apr-Jun 2016, p. 6. http:// peacemagazine.org/archive/v32n2p06.htm. Accessed 19 Mar 2020

Belyakov A (2019) “Chernobyl," Boeing and their lessons. https://fromchernobyltofukushima.com/boeing. Accessed 5 Mar 2020

Belz F-M, Peattie K (2009) Sustainability marketing: a global perspective. Wiley, Chichester

Bemporad R, Hebard A, Bressler D (2012) Rethinking consumption: consumers and the future of sustainability. BBMG, GlobeScan and SustainAbility. https://globescan.com/wp-content/uploads/2017/07/ Rethinking_Consumption_Consumers_and the_Future of_Sustainability_The_Regeneration_Roadmap.pdf. Accessed 19 Mar 2020

Bergen $T$ (2019) A new mural in Italy addresses affordable, clean energy. https://inhabitat.com/a-newmural-in-italy-addresses-affordable-clean-energy. Accessed 5 Mar 2020

Bisello A, Vettorato D (2018) Multiple benefits of smart urban energy transition. In: Droege P (ed) Urban energy transition: renewable strategies for cities and regions. 2nd ed. pp 467-490. https://doi.org/10.1016/B978-008-102074-6.00037-1

Bitcoin Energy Consumption Index (2019) Digiconomist. https://digiconomist.net/bitcoin-energy-consumption. Accessed 23 July 2019

Bloemers R, Magnani F, Peters M (2001) Paying a green premium. McKinsey Q 37(3):15-17

Bock P (2020) Greta Thunberg says EU law to tackle climate change is 'surrender'. Euronews. https://www. euronews.com/2020/03/04/greta-thunberg-in-brussels- 
as-eu-unveils-green-deal-plan-for-carbon-neutrality. Accessed 6 Mar 2020

Brown LR (2001) Eco-economy: building an economy for the earth. New York, W.W. Norton \& Company, Earth Policy Institute

Bullfrog Power (2018) Residential sign up. Bullfrog Power https://www.bullfrogpower.com/signup/signup.cfm? $\mathrm{p}=5$. Accessed 31 May 2018

Byelyakov O (2005) Environmentally friendly behaviour as a prerequisite for sustainable development in Ukraine. In: Platje J (ed) Urban and Rural Agro-Food Systems as a Factor of Local Sustainable Development - setting priorities and issues of governance. Econ Environ Stud 7:13-25

Calvert K (2015) Energy and society. In: International encyclopedia of the social \& behavioral sciences. Elsevier, Kidlington/Oxford, pp 615-620

Canadian Nuclear Safety Commission (2019) Potassium iodide (KI) pills. http://nuclearsafety.gc.ca/eng/reso urces/news-room/feature-articles/potassium-iodideKI-pills.cfm. Accessed 22 July 2019

Capella A (2016) Agenda-setting policy: strategies and agenda denial mechanisms. Organ Soc 23:79. https://doi.org/10.1590/1984-9230713. Accessed 22 July 2019

Case RA, Zeglen L (2018) Exploring the ebbs and flows of community engagement: the pyramid of engagement and water activism in two Canadian communities. J Community Pract 26(2):184-203

Castro-Alvarez F et al (2018) The 2018 International Energy Efficiency Scorecard. American Council for an Energy-Efficient Economy. https://aceee.org/sites/ default/files/publications/researchreports/i1801.pdf. Accessed 28 Feb 2019

CDKN (2015) Strategy for energy efficiency campaign. https://cdkn.org/wp-content/uploads/2017/07/Up-EEcommunications-campaign-strategy-1.pdf. Accessed 22 July 2019

Chawla L (1998) Significant life experiences revisited: a review of research on sources of pro-environmental sensitivity. J Environ Educ 29(3):11-21

Clifton K (2018) BBC in London put on lockdown over climate change protest by Extinction Rebellion. Evening Standard. 21 December. https://www.stan dard.co.uk/news/uk/bbc-in-london-put-on-lockdownover-climate-change-protest-by-extinction-rebelliona4024041.html. Accessed 25 July 2019

Creative Dynamo (n.d.) Ecotainment. https:// creativedynamo.net/ecotainment/. Accessed 17 July 2018

Dahlstrand U, Biel A (1997) Pro-environmental habits: propensity levels in behavioural change. J Appl Soc Psychol 27:588

Dhiman S (2018) Selfishness, greed, and apathy. In: Dhiman S, Marques J (eds) Handbook of engaged sustainability. Springer, Cham. https://link.springer. com/referenceworkentry/10.1007/978-3-319-531212_1-1. Accessed 19 June 2018

do Paço FA, Raposo BM, Filho WJ (2009) Identifying the green consumer: a segmentation study. J Target
Meas Anal Mark 17:17. https://doi.org/10.1057/ jt.2008.28

Dolliver M (2009) Convenience is the mother of conservation for Most. Adweek. http://www.adweek. com/news/advertising-branding/convenience-motherconservation-most-105739. Accessed 29 June 2018

Durham Radio News (2020) More than 32,000 orders for KI pills after false alarm at Pickering Nuclear: OPG. January 14. https://www.durhamradionews. com/archives/123885. Accessed 2 Mar 2020

Elnakat A, Gomez JD, Booth N (2016) A zip code study of socioeconomic, demographic, and household gendered influence on the residential energy sector. Energy Rep 2:21-27

Eskom (2015) Creating an energy awareness programme: behavioural change at work. http:/www.eskom.co.za/ sites/idm/Documents/AdvisoryServiceCreatingAnEne rgyAwarenessCampBrochure.pdf. Accessed 19 Mar 2020

Extinction Rebellion (2019) Climate change kills children: extinction rebellion mothers and babies stage mass 'feed-in' at party HQs. 2 December. https://rebellion. earth/2019/12/02/climate-change-kills-children-extinc tion-rebellion-mothers-and-babies-stage-mass-feed-inat-party-hqs/. Accessed 19 Mar 2020

Fast S et al (2016) Lessons learned from Ontario wind energy disputes. Nat Energy 1(2):15028

Fisher C, Bashyal S, Bachman B (2012) Demographic impacts on environmentally friendly purchase behaviors. J Target Meas Anal Mark 20:3-4

Fridays for Future (2019) Statistics/graph. https://www. fridaysforfuture.org/statistics/graph. Accessed $4 \mathrm{Mar}$ 2020

Gatersleben B, Steg L, Vlek C (2002) Measurement and determinants of environmentally significant consumer behavior. Environ Behav 34:335

Geiger S (2020) Twitter. March 1. https://twitter.com/ Sphiamia. Accessed 5 Mar 2020

Hallam R (2019) Now we know: conventional campaigning won't prevent our extinction. The Guardian. 1 May. https://www.theguardian.com/com mentisfree/2019/may/01/extinction-rebellion-non-viol ent-civil-disobedience. Accessed 23 July 2019

Hamid PN, Cheng ST (1995) Predicting antipollution behavior. Environ Behav 27(5):679-695

Henry G (2011) Malcolm Shepherd Knowles: a history of his thought. Education in a competitive and globalizing world. Nova Science Publishers, New York

Hodson J, Dale A, Petersen B (2017) The Instagram \#climatechange hashtag community: does it impact social capital and community agency? Int J Interdiscip Environ Stud 12(3):17-21

Howe RW, Disinger JF (1988) Environmental education that makes a difference - knowledge to behaviour changes. In: ERIC/SMEAC Environmental Education Digest, No. 4. https://www.ericdigests.org/pre-9215/ environmental.htm. Accessed 19 Mar 2020

IAP2 (2014) Public participation spectrum. https://cdn. ymaws.com/www.iap2.org/resource/resmgr/foundatio ns_course/IAP2_P2_Spectrum_FINAL.pdf. Accessed 10 Aug 2019 
IAP2 Australasia (2016). https://www.iap2.org.au/AboutUs/International-Year-of-Engagement. Accessed 11 Aug 2019

ISSP (2017) ISSP-CSP study guide. International Society of Sustainability Professionals. https://cdn.ymaws.com/com munity.sustainabilityprofessionals.org/resource/resmgr/ documents/program/credential/ISSP-CSP_Guide_Pre view.pdf. Accessed 19 Mar 2020

Johnston KA, Lane AB (2019) An authenticity matrix for community engagement. Public Relat Rev 45:101811

Kallakuri C et al (2016) The 2016 international energy efficiency scorecard. American Council for an Energy-Efficient Economy, Washington, DC

Kollmuss A, Agyeman J (2002) Mind the gap: why do people act environmentally and what are the barriers to pro-environmental behavior? Environ Educ Res 8 (3):239-260

Kotler P, Keller KL, Goodman M, Brady M, Hansen T (2019) Marketing management. Pearson, Harlow

Lee D, Newby H (1983) The problem of sociology: an introduction to the discipline. Unwin Hyman, London

Li J, Li N, Cui H, Wu Z (2019) Energy consumption of cryptocurrency mining: a study of electricity consumption in mining cryptocurrencies. Energy 168:160-168

Lichtl M (1999) Ecotainment: Der neue Weg im Umweltmarketing. Emotionale Werbebotschaften, Sustainability, Cross-Marketing, Wien

Liter of Light (2019) About liter of light. https://iteroflight. org/about/. Accessed 6 Mar 2020

Luchs MG, Walker NR, Irwin JR, Raghunathan R (2010) The sustainability penalty: potential negative effects of ethicality on product preference. J Mark 74(5):18-31

Lutzenhiser L (1993) Social and behavioral aspects of energy use. Annu Rev Energy Environ 18:247

Mackey RH Sr (1992) Translating vision into reality: the role of the strategic leader. US Army War College, Carlisle Barracks, $\mathrm{p} 10$

Maslow A (1998) Toward a psychology of being, 3rd edn. Wiley, New York

Meier A, Darwish M, Sabeeh S (2013) Complexities of saving energy in Qatar. In: ECEEE Summer Study Proceedings, pp 41-46. https://www.eceee.org/library/ conference_proceedings/eceee_Summer_Studies/2013/ 1-foundations-of-future-energy-policy/complexities-ofsaving-energy-in-qatar/. Accessed 19 Mar 2020

Meloche E (2012) Consumer segmentation. February Market Research Update 2012. saveONenergy Bi-Weekly Update. https://www.saveonenergy.ca/. Accessed 15 Mar 2018

Ministry of Energy (2017) Ontario's Long-Term Energy Plan. Queen's Printer for Ontario. https://files.ontario. ca/books/ltep2017_0.pdf. Accessed 19 Mar 2020

Ministry of the Solicitor General (2020). Investigation into the Emergency Alerts Sent on January 12, $2020 \mathrm{https}$ :// www.mcscs.jus.gov.on.ca/english/Publications/Investi gationemergencyalertssentJanuary $122020 . \mathrm{html}$. Accessed 6 Mar 2020

Mobilisation Lab (2015) Engagement Pyramid. https:// mobilisationlab.org/wp-content/uploads/2015/11/
Engagement-Pyramid_MobLab.pdf. Accessed 18 June 2018

Mobium Group (2015) Consumer segments. http://www. lohas.com.au/consumer-segments. Accessed 22 July 2019

Newman D. (2017) Community engagement driving force behind great customer experience. https://v3b.com/ 2017/07/community-engagement-driving-force-behin d-great-customer-experience/. Accessed 17 May 2018

OECD/IEA (2018) The future of cooling. https://webstore. iea.org/download/direct $/ 1036$ ?fileName=The_Future of_Cooling.pdf. Accessed 28 July 2019

Ontario Energy Board (2016) New OEB Consumer Engagement Framework. https://www.oebca/oeb/_Doc uments/Documents/Consumer_Voice_FAQ.pdf. Accessed 10 Aug 2019

Oswald Y, Owen A, Steinberger JK (2020) Large inequality in international and intranational energy footprints between income groups and across consumption categories. Nat Energy 5:231-239 https://doi.org/10.1038/ s41560-020-0579-8

Peloza J, White K, Shang J (2013) Good and guilt-free: the role of self-accountability in influencing preferences for products with ethical attributes. J Mark 77(1):104119

Petrova S, Gentile M, Mäkinen IH, Bouzarovski S (2013) Perceptions of thermal comfort and housing quality: exploring the microgeographies of energy poverty in Stakhanov, Ukraine. Environ Plan A Econ Space 45 (5):1240-1257

Pfeffer M, Stycos J, Mayone J (2002) Immigrant environmental behaviours in New York City. Soc Sci Q 83:64

Poortinga W, Steg L, Vlek C (2004) Values, environmental concern and environmental behaviour: a study into household energy use. Environ Behav 36:70-93

Popper N (2018) There is nothing virtual about Bitcoin's energy appetite. The New York Times. January, 21

Pothitou M, Varga L, Kolios A, Gu S (2017) Linking energy behaviour, attitude and habits with environmental predisposition and knowledge. Int J Sustain Energy 36(4):398-414

PricewaterhouseCoopers Global Power \& Utilities (2016) Customer engagement in an era of energy transformation. https://www.pwc.nl/nl/assets/documents/pwc-cus tomer-engagement-in-an-era-of-energy-transf ormation.pdf. Accessed 1 July 2018

Prochaska JO, Velicer WF (1997) The transtheoretical model of health behavior change. Am J Health Promot 12(1):38-48

Riemer M, Lynes J, Hickman G (2013) A model for developing and assessing youth-based environmental engagement programmes. Environ Educ Res 20 (4):552-574

Robinson KF, Fuller AK, Stedman RC et al (2019) Integration of social and ecological sciences for natural resource decision making: challenges and opportunities. Environ Manag 63:565. https://doi.org/10.1007/ s00267-019-01141-2 
Rosenblatt G (2010) The engagement pyramid: six levels of connecting people and social change. Retrieved from http://groundwire.org/blog/groundwire-engagementpyramid. Accessed 28 June 2018

Rushowy K (2018) Toronto schools want anti-radiation pills in case of nuclear incident at Pickering plant. https:/www.thestar.com/news/queenspark/2018/06/ 28/toronto-schools-want-anti-radiation-pills-in-caseof-nuclear-incident-at-pickering-plant.html. Accessed 12 July 2018

Schwarzinger S, Bird DN, Hadler M (2018) The "Paris lifestyle" - bridging the gap between science and communication by analysing and quantifying the role of target groups for climate change mitigation and adaptation: an interdisciplinary approach. In: Addressing the challenges in communicating climate change across various audiences, pp 375-397. https://link.springer.com/ chapter/10.1007\%2F978-3-319-98294-6_23. Accessed 19 Mar 2020

Stone E (2017) Drones spray tree seeds from the sky to fight deforestation. National Geographic. November 29, 2017 https://news.nationalgeographic.com/2017/ 11/drones-plant-trees-deforestation-environment/. Accessed 22 July 2019

Tardy F, Lee B (2019) Building related energy poverty in developed countries - past, present, and future from a Canadian perspective. Energ Buildings 194:46-61

Thunberg G (2019) No one is too small to make a difference. Penguin Group. ISBN: 9780141992716

TNS (2008) Our Green World: an international survey covering 17 countries into how green we really are. http://www.tnsglobal.com/_assets/files/TNS_Market_ Research_Our_Green_World.pdf. Accessed 10 June 2018

Trend Briefing (2013) Guilt-free consumption. Why guiltfree is the new luxury for consumers, and the Holy Grail for businesses. November. Trend Briefing

Truby J (2018) Decarbonizing Bitcoin: law and policy choices for reducing the energy consumption of
Blockchain technologies and digital currencies. Energy Res Soc Sci 44:399-410

Tyson CB (2003) Strategic environmental communication: communicating strategies for influencing environmental behaviors. 2nd ed. Xanedu Publishers. ISBN 978-15320-5631-4

United Nations (2019) Sustainable Development Goals Indicators. https://unstats.un.org/sdgs/indicators/data base/. Accessed 23 July 2019

White K et al (2019) The Elusive Green Consumer. Harv Bus Rev. https://hbr.org/2019/07/the-elusive-greenconsum er. Accessed 23 July 2019

Whyte WH (1950) Is anybody listening? Fortune Magazine (September). New York: Time, Inc, p 77

Wilson A (2019) The heart of community engagement. Practitioner Stories from across the globe. Routledge, London/New York

Wong V, Turner W, Stoneman P (1996) Marketing strategies and market prospects for environmentally friendly consumer products. Bri J Manag 7:263

World Bank (2018) Designing communication campaigns for energy subsidy reform. Good Practice Note 10. http://documents.worldbank.org/curated/en/93955153 0880505644/pdf/ESRAF-note-10-Designing-Commu nication-Campaigns-for-Energy-Subsidy-Reform.pdf. Accessed 23 July 2019

Yankelovich D, Meer D (2006) Rediscovering market segmentation. Harv Bus Rev 84(2):122-31, 166

Young R et al (2014) The 2014 international energy efficiency scorecard. American Council for an Energy-Efficient Economy. https://www.aceee.org/researchreport/ e1402. Accessed 19 Mar 2020

Zalucky H (2019) Personal communication. E-Mail. 25 July 2019

Zhang F (2019) In the dark: how much do Power sector distortions cost South Asia? South Asia Development Forum. World Bank, Washington, DC

Zhou K, Yang S (2016) Understanding household energy consumption behavior: the contribution of energy big data analytics. Renew Sust Energ Rev 56:810 